\title{
17 CREATING ABORIGINAL \\ PLACENAMES: APPLIED \\ PHILOLOGY IN ARMIDALE CITY
}

\author{
Nicholas Reid
}

\section{ARMIDALE CITY COUNCIL'S POLICY FOR LOCAL PLACENAMING}

In a move progressive for local councils at the time, Armidale City Council (henceforth ACC) initiated a draft policy in 1994 for placenaming in the City. An interim policy commenced in January 1994, and the policy proper was adopted in June 1996. The push to develop a policy for placenaming was born of dissatisfaction with the ad hoc and inconsistent bases by which names were being applied.'

The stated aims of the ACC's 1996 policy are to:

- provide a consistent approach to placenaming;

- increase the use of placenames with local historical, botanical and zoological associations;

- provide the local community and intending developers with clear information on Council's requirements for placenaming;

- simplify administration of road naming by introducing a procedure for such matters to be dealt with by Council officers under delegation.

As this last point makes clear, the policy is intended to be used mostly in respect of road naming, but the guidelines within it can 'be applied to any geographic placenaming in Armidale', including buildings, hills, parks, etc. The policy does not involve plans to rename any existing places, but rather is intended to form the basis for coordinated future naming practices.

An important part of the ACC's policy is the development of a Register of Placenames. The register is a list of words and names of local regional significance. All future placename choices in Armidale must be drawn from this list. The Register is organised into the following eight categories:

Often the first names of the spouses and children of developers.

L. Hercus, F. Hodges and J. Simpson, eds, The Land is a Map: placenames of Indigenous origin in Australia, $24 \mathrm{I}-254$. Canberra: Pandanus Books in association with Pacific Linguistics, 2002.

(C) Nicholas Reid 
Aboriginal

Architects, Surveyors

Educational, Cultural

Miscellaneous Historical
Medical Associations ${ }^{2}$

Vietnam Veterans ${ }^{3}$

WW1 Ex-Servicemen

WW2 Ex-Servicemen

The procedures involved in developing the Policy and the Register of Placenames were these:

- Linguist to investigate the known sources of Anewan, and provide a report to ACC including a list of 'words suitable for placenaming purposes'.

- The draft report is distributed to a range of groups for comment, including AIATSIS, Armidale Aboriginal Cultural Centre and Keeping Place, Northern Tablelands Regional Aboriginal Lands Council, Geographic Names Board of NSW. The report is also given to the Aboriginal Community Committee (henceforth $\mathrm{AbCC}$ ) for comment and further distribution to local Aboriginal organisations.

- The Register scrutinised by ACC and list revised in view of feedback received from community and relevant groups. Register further revised at an ACC placenames workshop.

- Register of placenames is posted in Armidale for six weeks for community feedback, before being adopted as policy in June 1996.

- Future applications for street names to follow procedures set out in policy. Once proposed names are approved by AbCC, ACC notifies Geographical Names Board of NSW, Australia Post, Telstra, Dept of Conservation and Land Management, Land Titles Office, Dumaresq Shire Council and local emergency services. Placenames other than street names to be referred to the Geographical Names Board of NSW for approval and gazettal.

The Policy endorses the following criteria to be used in assessing proposed placenames (this is a reduced version of 18 criteria, many of the others are not relevant to the Anewan project and are thus not given here). Names should be:

- appropriate to the physical, historical or cultural character of the locality;

- not duplicates, or too similar to names used in surrounding shires, or elsewhere within the shire;

- thematic names with an historical, botanical or zoological background are generally preferred;

- names derived from the language of the Indigenous population of the district are also welcomed, and should be approved by the Aboriginal Community Committee prior to use;

- euphonious names (i.e. pleasing to the ear, easy to pronounce) shall be used.

[ACC Draft Policy document, 1994]

2 This refers not to any organisations, but to the names of local individuals (doctors, surgeons, etc.) who have contributed to the region in the area of medical service.

3 Veterans of the Korean War seem not to have been considered, highlighting a media debate about their invisibility at the time of writing. 


\section{THE ANEWAN PROJECT}

Armidale City Council asked me to undertake research into the local language and provide a list of 'relevant placenames'. The language traditionally associated with this area is fairly clearly Anewan (Nganyaywana). Although by the time any records were made the Anewan people had already suffered massive social disruption, most early sources fairly uniformly describe Anewan as covering an area of which Armidale sits in the centre. In 1903 Mathews notes that "The remnants of the Anewan tribe are scattered over the southern half of what is known as the "tableland" of New England, including Macdonald River, Walcha, Uralla, Bendemeer, Armidale, Hillgrove, and other places' (Mathews 1903:251). These days, descendants of speakers of Gamilaraay, Gumbayngir, Dhungutti and Bundjalung also have long-standing established histories with the region. I expected to find interest from the AbCC in extending the range of languages used to assemble the list, but there was general agreement that Anewan was the appropriate language.

\subsection{Anewan language sources}

There are no longer any Anewan descendants with active speaking knowledge of this language, though there is knowledge of certain words. The available written sources of information are mostly the writings of Europeans, and generally the work of people who were enthusiastic amateurs at best. The bulk of material comes from contributions to journals like Proceedings of the American Philosophical Society, Proceedings of the Royal Australian Historical Society, Mankind, etc. by R.H. Mathews and J. MacPherson in the first two decades of this century. A full listing of the sources is provided at the end of this paper.

The single significant exception is Crowley's (1976) article 'Phonological Change in New England' which focuses on phonological changes that for a while disguised the relatedness of Anewan to the rest of Australian languages. While Crowley's work is a rigorous and careful piece of scholarship, it is of course limited by the sources he is dependent on. $\mathrm{He}$ predominantly uses Mathews, also relies on MacPherson, and provides a phonemicised list of some of Mathews' vocabulary.

The existing data reveal no placenames as such (i.e. words that Anewan speakers used to name places in the specific locality where the City of Armidale now stands). The nearest thing is a very short list of 'Walcha District' names in the unidentified 1904 source, but these were excluded for lack of immediate local significance. In the absence of 'real placenames', the Aboriginal Community Committee decided that the next best thing would be to document known Anewan words and make them available as potential placenames.

The existing records allowed us to produce a phonemicised list of 271 words. From this list we needed to choose words to go on the register, and consider how best to represent them. Sections 3 and 4 of this paper deal with each of these issues in turn. However, before addressing these, we need to complete our background information by considering the sound system of Anewan. 


\subsection{Sounds of Anewan}

The inventory of Anewan phonemes contains the following 14 consonants and 3 vowels.

consonants

$\begin{array}{llllllll}\text { stops } & & b & d & j & g & i & \\ \text { nasals } & m & n & n y & n g & & & \\ \text { laterals } & l & l y & & & & a \\ \text { trill } & & & r r & & & \\ \text { continuant } & & & r & & & \end{array}$

Anewan has aroused some interest among linguists because it has undergone some interesting historical sound changes. Notably, it has lost the initial syllable, or initial consonant of many words. The language today is known as Anewan, but is reconstructable as Nganyaywana. For a while it was considered that Anewan was not demonstrably related to other Australian languages, but this notion has been effectively disproved. Demonstrating the sound changes that have taken place in Anewan, and thus proving that it is in fact a typical Australian language, is the main thrust of Crowley (1976). One interesting by-product of these phonological changes is an unusually high number of homophones in the short list of available Anewan words, for example:

$\begin{array}{llll}\text { janda } & \text { 'goanna' } & \text { janda } & \text { 'bull ant' } \\ \text { rrula } & \text { 'male' } & \text { rrula } & \text { 'stone' } \\ \text { rrala } & \text { 'hair' } & \text { rrala } & \text { 'gumtree species' }\end{array}$

Another by-product of initial loss is the fairly high frequency in Anewan of word-initial nasal/stop clusters, for example:

\begin{tabular}{|c|c|c|c|}
\hline mbunja & 'bandicoot' & nduda & 'spear shield' \\
\hline nyjunda & 'down there' & nggurra & 'leaf' \\
\hline
\end{tabular}

and also other initial cluster types unusual by Australian standards, for example:

lwanyja 'geebung tree'

\section{CHOOSING WORDS TO GO ON THE REGISTER}

In drawing up my report to ACC I provided a list of every known Anewan word, together with its meaning, a Phonemic Representation, and a Recommended Spelling. As a linguist and highly conscious of the preciousness of each and every word of a language about which so little is known, I found myself reluctant to eliminate any words at all. This reluctance was further heightened by a certain uneasiness about the highly subjective basis of choosing 'appropriate' and 'euphonious' words. So I had a two-way bet. I included every word, but chose to additionally provide a pronunciation guide for only a subset of 57 words that seemed to meet the expressed expectations. This in effect provided a reduced subset of words, but it came with an explanation that the process was subjective, and that any other words meeting 
the collective fancy of the ACC could readily be given pronunciation guides. (See the extract of the full list attached as Appendix 1.)

I now want to address the kinds of criteria I employed in selecting this subset of 57 words. The original brief from the ACC focused on sounds only, requesting that words be 'pleasing to the ear, easy to pronounce'. On discussion with various councillors and members of the Aboriginal Community Committee, I took this highly subjective direction to be sensitive to:

sound: broadly fit English phonotactics

visual look: words that are not too long or complicated

\subsection{Choosing words by sound}

The permissible patterns of sounds that can occur next to each other in Anewan are quite different from those permissible in English. Phonotactic considerations led us to set aside words with initial velar nasals (ngana 'fast') and initial nasal/stop clusters (nggada 'fog', $m b w i$ 'swim').

\subsection{Choosing words by size}

In the initial brief it was stressed by ACC that words should not be too long or complicatedlooking. After receipt of the report, the AAC workshop rejected the two words imboodoonga and roowalgoonda for violating these criteria. I am intrigued by this rejection, for it operates against a dominant notion operating in the minds of almost everyone I spoke to about this project: that Aboriginal words should be long. Many people (both Aboriginal and White) expect good Aboriginal placenames to have a four-syllable CVCVCVCV pattern where $\mathrm{Cl}$ and $\mathrm{C} 3$ are peripheral consonants, and $\mathrm{C} 2$ and $\mathrm{C} 4$ are voiceless stops, laterals or rhotics, tend towards reduplication, and should ideally sound like 'Parramatta' or 'Muttaburra'. Appreciation of such placenames is an important theme in Anglo-Australian culture, and I recognise this notion in myself as much as in others.

In Armidale there are many street names based on monosyllabic words (Hay St, John St, Crest Rd, etc.). Those subjective demands of being 'euphonious' and 'melodious' seem not to apply to these English street names. No-one associated with this project was at all interested in monosyllabic Aboriginal placenames. Setting aside the word class issues (most Anewan monosyllabic words in the list are verbs, this/that, yes/no), possibilities like Na St, Bwi Rd, were rejected all round. Euphony and melody, it seems, demand syllabic weight. Consider these word syllable count statistics across the three stages of trimming the list.

\begin{tabular}{|lr|c|c|}
\hline 172 nouns, full list & 57 nouns, NR report & 33 nouns, final register list \\
\hline 1 syllable: & 2 & 0 & 0 \\
2 syllable: & 93 & 10 & 6 \\
3 syllable: & 76 & 38 & 24 \\
4 syllable: & 11 & 9 & 3 \\
\hline
\end{tabular}


Although 51 per cent of nouns in the data are disyllabic, in the final list of words chosen for the register just six of 33 are disyllabic.

\subsection{Choosing words by meaning and wordclass}

The original brief from $\mathrm{ACC}$ established meaning as a criterion to be employed in the choice of words for the register, in only these general terms:

Thematic names with an historical, botanical or zoological background are generally preferred.

We thus first extracted all non-referential words - mostly pronouns (we all, you two), adjectives (slow, big), demonstratives (this, that) and particles like 'yes' and 'no'. We also removed most verbs ( $m b w i$ 'swim', $d w a$ 'cry') on the grounds that even though they typically had lexical content, they failed the referentiality criterion.

All people involved on the ACC and AbCC were unified in their belief that only nouns make good potential placenames. This favouring of nouns seemed justifiable; the bestowal of a name is the evocation of some referent. And it is thus the very non-referentiality of words from other wordclasses, that makes them unsatisfactory placenames. Do you find English examples such as Slow St, What St, Then St, etc. to be satisfactory street names? Nevertheless I had some qualms about throwing out every non-noun, and slipped a few 'euphonious sounding' ones in to see how they fared under ACC scrutiny (two pronouns, three adjectives). Not well; they were promptly removed by the $A b C C$, the final list includes no pronouns, adjectives or verbs. Every word considered suitable for the register is a noun referring to an animal (just over half of the 33 words), plant, artefact or landscape feature, plus one word indaralla 'totem of medicine man', which even to people with little knowledge of Aboriginal cultures (or maybe especially to them) sounds satisfactorily ripe with Aboriginal cultural meaning.

Note that this focus on nouns as being the best tokens of placenames is quite at odds with traditional patterns of placenaming. Hercus and Simpson (this volume) comment on the widespread use of verbal expressions, often full clauses, in naming places in terms of activities that were carried out at them.

Word meaning was a criterion for the rejection of a few words considered 'undesirable'. While R.H. Mathews' careful recording of the verb 'masturbate' in nearly every word list he provides is no doubt a valuable inclusion, I suspected it would not pass muster with the City Councillors. I also unilaterally weeded out dunya 'penis' and bula 'anus' on the assumption that these would not be seized upon as appropriate placename material.

\subsection{Further pruning the list}

The list of 57 words that I provided to Council in my report underwent three further prunings. The Aboriginal Community Committee removed the following words on the grounds that they were inappropriate. No details were provided, but note that these words (including the three adjectives and two pronouns that I slipped in) all have poor referentiality.

$\begin{array}{ll}\text { Gwanga } & \text { children } \\ \text { Aroonba } & \text { good } \\ \text { Irabilla } & \text { mother } \\ \text { Argana } & \text { section name }\end{array}$




$\begin{array}{ll}\text { Noombadja } & \text { slow } \\ \text { Lidjirana } & \text { small } \\ \text { Nunnyaburra } & \text { we (PL INC) } \\ \text { Nanambinga } & \text { we (PL EX) }\end{array}$

The Council officer responsible for street naming removed the following words because of similarity to other words, as specified below. This action was explained in terms of practicalities, similarities in names potentially causing problems for emergency services.

$\begin{array}{ll}\text { Igina } & \text { too similar to Igana } \\ \text { Imboonda } & \text { too similar to Imbandja } \\ \text { Imboondja } & \text { too similar to Imbandja } \\ \text { Oowurra } & \text { too similar to Oorala } \\ \text { Lyburra } & \text { too similar to Lumburra } \\ \text { Roogala } & \text { too similar to Rujala } \\ \text { Woongala } & \text { too similar to Rujala } \\ \text { Naiya } & \text { too similar (in pronunciation) to Jundja }\end{array}$

The Council officer also removed one word from the list due to concerns about its similarity to an English word:
Loona
'too easily bastardised to Loony'

And two four-syllable words were removed because of their perceived length:

$\begin{array}{ll}\text { Imboodoonga } & \text { 'too long' } \\ \text { Roowalgoonda } & \text { 'too long' }\end{array}$

The following words were removed at a Council workshop as they were considered 'inappropriate given the English translation' (ACC).

$\begin{array}{ll}\text { Ilgaiwa } & \text { 'summer' } \\ \text { Iluna } & \text { 'darkness' } \\ \text { Jarrwanba } & \text { 'winter' } \\ \text { Nura } & \text { 'sun' } \\ \text { Yoongarra } & \text { 'rain' }\end{array}$

The exclusion of these words surprised me, for although the cited reasons for exclusion seemed to be semantic ones, I could see no consistency in excluding yoongarra 'rain' but leaving arribana 'hail' and igana 'snow' on the list, nor in excluding nura 'sun' but leaving jundja 'moon'. However, by this stage of the process the input from the linguist was completed.

If the perceived similarity surprises you, then that makes two of us. 


\section{DECIDING HOW TO WRITE WORDS}

\subsection{Phonemic and non-phonemic spelling}

In the full list words are provided in three forms: a 'Phonemicised' form, in a 'Recommended Spelling' form, and a 'Pronunciation Guide'. The intention of the last was to provide Council with a resource that will be of assistance in handling inquiries from the public about the pronunciation of these words.

Phonemicised spelling refers to a writing system that uses an invariant symbol for each contrastive unit of sound in the language. The phonemicised forms are based on Crowley's (1976) reconstruction of the Nganyaywana (Anewan) phonemic inventory.

For placenaming purposes we decided that a truly phonemic writing system for Anewan words would be inappropriate, given the intended purpose and audience. The ACC made it clear that placenames must be easily interpretable and their pronunciation self-evident to native speakers of English, stressing the practical importance of avoiding ambiguity in, for example, directing an ambulance to a certain address, etc. The target audience in this case is the residents of Armidale who are predominantly speakers of varieties of Australian English, including Aboriginal English.

The writing system used in the 'Recommended Spelling' list differs from the phonemic representation. The rationale behind this writing system is, on the one hand, to preserve the phonemic system where possible. On the other hand it has been influenced by the fact that the 'users' of these words are likely to be speakers of standard English-only, or in some cases of varieties of Aboriginal English. It is desirable therefore that these users be able to look at these words in written form and be able to guess at an obvious and fairly uniform pronunciation for them. To this end, the 'obvious pronunciation' principle tends to win out over the 'maintain phonemic accuracy' principle.

The Recommended Spelling draws on the principles of non-phonemic re-spelling, where the ordinary spelling rules of English are used to best represent pronunciation, rather than systematically using one symbol for each phoneme. In this I drew on work by Helen Fraser who has used non-phonemic English spelling rules to develop pronunciation guides for dictionaries. Her idea is that people frequently malign English spelling for its numerous inconsistencies, but ignore the underlying regularity. They forget that the myriad exceptions to every rule, are just that: exceptions to rules. Using 26 symbols for 44 phonemes may sound disastrous, but using 26 symbols and their spatial arrangements allows for the regular contrast of further sets of sounds, albeit in a non-phonemic way. Consider the regular representation of the $\left[\mathrm{e}_{\mathrm{I}}\right]-[æ]$ contrast using the 'silent-e spellings' (hate/hat, pate/pat, fate/fat, mate/mat, etc.), and the regular representation of short vowels through the doubling of following consonant, etc. The influence of these ideas can be seen most clearly in the Pronunciation Guide, but also in the Recommended spellings.

\subsection{Making Anewan words more like English}

There are some features of Anewan words that make them difficult for English speakers to pronounce. We had already weeded out words that obviously violated the phonotactic rules of English. For example, we excluded words that began with the velar nasal 'ng' sound, and with clusters like that in $m b w i$ 'swim'. The phonologies of Anewan and English also differ in other 
ways. In some respects Anewan makes distinctions that English does not make. For example, in Anewan there are two ' $r$ ' sounds, written with a single ' $r$ ', and with a double ' $r$ '. Conversely in other respects English makes distinctions that Anewan does not make. For example, English distinguishes between voiceless stops (like $p, t$ and $k$ ) and voiced stops (like $b, d$ and $g$ ), while Anewan does not. After testing out various spelling systems, we proposed a number of simplifications that made Anewan words more pronounceable to English speakers. These pronunciations were not entirely innovations. Most of them are changes that have come about in the way that English-speaking people of Anewan descent now pronounce these Anewan words. Let us now consider some of the practices we have adopted.

\subsubsection{Stop voicing}

In Anewan there is no systematic contrast between 'voiced' and 'voiceless' pairs of stops (like $p$ and $b, t$ and $d, k$ and $g$, etc.), and so only the voiced symbols are used for a phonemic writing system. Sources like Mathews suggest that word-initially stops tend to be voiceless, and in the middle of words they tended to be voiced (post-nasally and inter-vocalically). For the purposes of this project, where users of these words will be speakers of English and/or Aboriginal English, we could have chosen to use the voiceless stop symbols in word-initial position in order to achieve phonetically closer pronunciations. However, for the sake of simplicity, and because the majority of stops in the data are either inter-vocalic or post-nasal, we chose to use just voiced stop symbols for the Recommended Spelling.

\subsubsection{Types of ' $\mathrm{r}$ '}

Anewan had a distinction between two rhotics, a continuant represented phonemically as $/ \mathrm{r} /$ and a trill represented phonemically as $/ \mathrm{rr} /$. In the Anewan words now known to Anewan descendants, who are speakers of standard and Aboriginal English, this distinction between rhotics has been neutralised, with both sounds now realised as the continuant [I]. As this neutralisation has operated under influence from English, we decided that it suits our purposes. The writing system we have chosen uses both ' $r$ ' and ' $r$ ', but we intend no pronunciation difference by these. In word-initial position, the trill (e.g. Rrundja 'emu') was considered 'too foreign-looking', so all word-initial trills have been rewritten using a single ' $r$ ' (thus Rundja 'emu'). We anticipate that syllable-initial ' $r$ ' or ' $r r$ ' will always be pronounced as a continuant, and that syllable-final ' $r$ ' or ' $r r$ ' will be not pronounced at all. Nevertheless, we have used both ' $r$ ' and ' $r$ ' in the word list, and feel that this serves another function - to provide an Aboriginal flavour to the visual word. Many well-known anglicised Aboriginal words, such as 'kookaburra', 'Parramatta', etc. feature double $r$ 's, and there was general agreement among the $\mathrm{AbCC}$ members that this was a salient indication of the Aboriginal origin of Anewan words. So in general we have used ' $r$ ' intervocalically (e.g. burra 'kangaroo rat'), except where it may conflict with vowel length considerations (thus, lara 'rock'). 


\subsection{3 ng and ngg}

The sounds $/ \mathrm{ng} /$ and $/ \mathrm{ngg} /$ present difficulties because of the common failure of English spelling to distinguish between them (e.g., 'singer' versus 'finger', etc.). Systematic ways of representing them tended to be undone by English speakers' inclination to read 'anga' as [ $\wedge \mathrm{\eta g} \Lambda]$. We have chosen to spell /ng/ with 'ng', and /ngg/ with 'ngg', and hope that reference to a pronunciation guide will provide the correct pronunciation to any interested person. However, we also accept that variant pronunciations may be inevitable.

\subsection{4 a and $\mathrm{u}$}

The vowels $/ a /$ and $/ \mathrm{u} /$ present some real difficulties. Spelling 'parakeet'/yimbangga/ as yimbangga tends to trigger the [ae] vowel. Trying to force short $[\Lambda]$ vowel by writing ' $u$ ' and doubling the following consonant works well in straight intervocalic environments (e.g. /arrgana/ as argunna 'boomerang'). However, consonant doubling works less well for /ngg/ sequences: writing /yimbangga/ as yimbungga worked best - but occasionally yielded [jimbung $\Lambda$.

\subsubsection{Lost initial syllables}

Some Nganyaywana words begin with clusters of homorganic nasal/stop, and early recorders like Mathews mis-heard these as having an initial vowel. For example, he records 'imboanda' for 'kangaroo', which Crowley reconstructs as /mbanyja/. Reluctant to throw out too many words, we took the decision to 'save' these words by re-introducing an initial vowel, giving imbandja. In the case of /mbangga/ 'parakeet', we re-introduced a glide as well, giving yimbungga, using knowledge from a neighbouring language to inform our choice of sounds. Two factors made this 'fiddle' easier. If hearing these words with an initial vowel was a 'natural mistake' for the likes of Mathews, then it seemed fair to allow contemporary English speakers the same pronunciation. Secondly, to some members of the AbCC, having learned of the historical fact of initial-syllable loss in Anewan, this seemed to be a historically informed re-introduction, as in a sense 'a vowel really used to be there'.

\subsubsection{Stress}

In addition to non-phonemic re-spelling, we have provided an indication of word stress by bolding certain syllables in the Pronunciation Guide (e.g. 'brolga' is roo-wal-goon-da, rather than say roo-wal-goon-da, etc.). There is no information on word stress patterns in any of the early sources, so we have no certain knowledge of which syllables of Anewan words were stressed. We could perhaps make intelligent guesses based on patterns found in other NSW languages, but even if we did know this, the English-speaking residents of Armidale would pronounce these words with Australian English stress patterns. We see no point in any attempt to be prescriptive here, so in providing information about syllable stress, we are merely codifying the pronunciation that local Aboriginal people currently give these words, and which we believe Anglo speakers of Australian English will also naturally give these words. 


\section{ATTITUDES TO PHONOLOGICAL ADAPTATIONS}

In coming up with a short list of Anewan words to be used for placenaming purposes, we began by examining all the sources and producing a phonemic listing of all known Anewan words. However, we have gone well beyond serving up Anewan words in their pristine form. As $\S 4$ makes clear, we have engaged in a series of practices intended to render Anewan words in a form that both makes them pronounceable to speakers of standard Australian English, and reflects the way in which English-speaking Anewan descendants now say these words. These practices have resulted in quite significant changes, such as the neutralisation of certain phonemic contrasts, the imposition of English stress patterns, and the partially inconsistent representation of some sounds. Needless to say, many of these practices are at odds with contemporary descriptive linguistic practice in Australia. Much of the early description of Aboriginal languages by amateur linguists yielded data hampered by these very features. In a day and age when well-trained linguists bring higher levels of skill to the task, how can we excuse such sloppy work?

In dealing with this question, we need to consider whether this work is descriptive, i.e. is it involved in describing Anewan words, or is it about commodification - creating from Anewan materials resources that did not exist in Anewan itself. We also need to consider what are feasible expectations when it comes to pronunciation. Can English-speaking Australians, of both Anglo- and Aboriginal descent, be expected to pronounce these words in the same way that a speaker of Anewan would have? Clearly not! Anyone whose first language is English, and who does not know Anewan, will pronounce these words in a non-Anewan way, and a host of articulatory factors contributing to accent will determine this - including word stress, and allophony, and some of the other factors discussed in $\$ 4$. Clearly, the expectation that English speakers will pronounce the words of any other language just as native speakers of those languages would is not feasible.

Indeed there are some very public failures in this regard. Two highly successful authors, Ngaio Marsh and Ngaire Thorpe, have written in English and carefully and conscientiously maintained their Maori first names. However, English speakers have proved very poor at saying these names with initial velar nasals. While writing this paper, I rang around several bookshops out of curiosity, and in all cases these authors were described to me as [nəgerui] or [nəgeə] (for Ngaire) and as [nəgaıu] (for Ngaio).

It is probably true that loanwords tend to exhibit greater variation in pronunciation than do other words. For example, some English speakers say [xєstəıã] for 'restaurant', while others say [IEstə.IDnt]. There are various motives underlying this variation within a speech community with regard to the pronunciation of loanwords, ranging from a display of knowledge of the source language, to more socio-political motives such as the signalling of solidarity, etc. There is evidence that widespread intentional accommodation in matters of pronunciation is possible across a speech community where such motivations exist. For example, while speakers of Australian English say [mauni] for 'Maori', speakers of New Zealand English very distinctively say [mauri] with a flap instead of a continuant. Similarly, Julia Roberts (pers. comm.) notes the rapid increase in the last two years among young white South Africans of pronouncing language names like Xhosa with an initial click, rather than an initial velar stop. The increased Western interest in ethnicity over the last decade has also possibly led to an increased interest in the 'correct pronunciation' of words known to come from another language. Whether or not such targeted pronunciations are actually like native speaker ones is probably not the point. Even those people who deliberately adapt their phonology to best replicate the source of the loanword, for whatever reasons, typically do not 
achieve this without some knowledge of the source language. However, perhaps it is enough to be seen to be trying. This kind of position would appear to lie behind Australian Broadcasting Corporation policy on the pronunciation of words and names from other languages. Often these are not quite as they should be in the source language, but they do represent a distinctive departure from the typical Australian English pronunciation.

In this area where socio-political motivations intersect with phonological competencies, little seems to be known about how far such 'accommodation' might go. It will be very interesting in coming years to follow the success of attempts to establish within contemporary Australian English loanwords from Aboriginal languages which significantly violate the phonotactic and phonological rules of English. For example, the Kaurna word Ngamatyi which is a name for the Adelaide place known in English as 'Victoria Square' (Amery \& Williams this volume) can be 'reinstated' and even have its correct pronunciation modelled by a Kaurna speaker. However, ultimately its fate and its pronunciation as a loanword into English are not in the hands of prescriptivists who wish to impose a 'correct' pronunciation. Ultimately the wider speech community of Adelaide residents will settle on a pronunciation of such words, a pronunciation that is largely shaped by their mother tongue phonology.

Many of the contributions to this volume detail attempts to carefully record and preserve Aboriginal names for places, and are characterised by a concern for faithfully describing the meanings and pronunciations of identified toponyms. This project is rather different, and some of the steps we have taken may well strike you as being a little cavalier, involving as it has: guessing at word classes; neutralising some phonemic distinctions; imposing the word stress patterns of another language; and selecting a group of words whose syllabic length and phonotactic structure are not representative of Anewan as it once was. And to pre-empt an English pronunciation of these Anewan words, and to deliberately employ a spelling convention that best represents that pronunciation, has been an act that has drawn criticisms of tokenism $^{5}$ from some quarters. But this work is not descriptive, it is not about describing Anewan. Rather it has involved serving up words of Aboriginal origin to an English-speaking audience, to create a commodity from Anewan resources that did not exist in Anewan itself. It is language engineering not language description.

5 Indeed at the Canberra workshop where this paper was first given, one commentator used this exact expression. 
Table 1: Final 33 words placed on the Placenaming Policy Register

\begin{tabular}{|l|l|l|l|}
\hline Meaning & $\begin{array}{l}\text { Recommended } \\
\text { spelling }\end{array}$ & $\begin{array}{l}\text { Pronunciation } \\
\text { guide }\end{array}$ & $\begin{array}{l}\text { Phonemicised } \\
\text { spelling }\end{array}$ \\
\hline 'apple tree' & Doonba & doon-ba & dunba \\
\hline 'bird (gen)' & Bilunnya & bi-lunn-ya & bilanya \\
\hline 'blacksnake' & Alinnya & a-linn-ya & alinya \\
\hline 'black cockatoo' & Wilara & wi-lah-ra & wilara \\
\hline 'boomerang' & Argunna & ar-gunn-a & arrgana \\
\hline 'camp' & Oorala & oo-rah-la & urala \\
\hline 'crab' & Jumbunna & jum-bunna & jambana \\
\hline 'curlew' & Rilwinoo & ril-win-oo & rrilwinu \\
\hline 'eaglehawk' & Lumburra & lum-burra & lambara \\
\hline 'flying fox' & Ramana & re-mahn-na & rramana \\
\hline 'forest oak' & Riwilla & re-willa & rriwila \\
\hline 'goanna (black)' & Rujala & roo-jah-la & rrujala \\
\hline 'grass tree' & Doonboora & doon-boo-ra & dunburra \\
\hline 'hail' & Arribunna & ah-ri-bun-na & arribana \\
\hline 'ironbark' & Girunba & gi-run-ba & girranba \\
\hline 'kangaroo' & Imbandja & im-ban-dja & mbanyja \\
\hline 'kangaroo rat' & Burra & bah-ra & barra \\
\hline 'koala' & Lawunnya & la-wunn-ya & lawanya \\
\hline 'moon' & Jundja & jun-dja & janyja \\
\hline 'mountain ash' & Oowinba & oo-win-ba & uwinba \\
\hline 'parakeet' & Yimbungga & yim-bung-ga & mbangga \\
\hline 'pelican' & Wooyara & woo-ya-ra & wuyara \\
\hline 'plover' & Jaringga & jah-ring-ga & jarringga \\
\hline 'rock (large, flat)' & Lara & lah-ra & lara \\
\hline 'snow' & Igana & ee-gah-na & igana \\
\hline 'swan' & Juwoola & dju-woo-la & juwula \\
\hline 'totem of medicine man' & Indaralla & in-da-rahl-la & ndarrala \\
\hline 'tree' & Dala & dah-la & dala \\
\hline 'turtle (stinking)' & Wirra & wi-ra & wirra \\
\hline 'uphill' & Indabaiyee & in-da-bai-yee & ndabayi \\
\hline 'wallaroo' & Lamala & la-ma-la & lamala \\
\hline 'water' & Yoogoonda & yoo-goon-da & ugunda \\
\hline 'white cockatoo' & Yirrbadja & yirr-bah-dja & irrbaja \\
\hline & & & \\
\hline
\end{tabular}

\section{REFERENCES}

Buchanan, F.J.,1901, Aboriginal words and meanings from Ee-na-won. Science of Man 4(4):64-65.

Crowley, T., 1976, Phonological change in New England. In R.M.W. Dixon, ed, Grammatical Categories in Australian Languages, 19-50. Canberra: AIAS. 
Fraser, H., 1996, Guy-dance with pro-nun-see-ay-shon: a consideration of how the everyday spelling system can be used more effectively than phonetic symbols in English pronunciation guides. English Today 12(3):28-37.

Hoddinott, W., Fieldnotes on Anewan. AIATSIS MS 2126/1. Item 8.

Laves, G., n.d. [probably 1929], A single text in 'Anewan' by Jack Malone at Bowraville. Laves Papers AIATSIS MS 2189 Box 2.

MacPherson, J., n.d., Comparative vocabulary of 'Enneewin', Ngarbal, Yugambal, Bigambal, Guyambal, Ngarrabul, and Bundel(la)'. MS.

- 1904, Ngarrabul and other Aboriginal tribes. Proceedings of the Linnean Society of New South Wales, 677-684.

- 1930, Some Aboriginal place names in northern New South Wales. Royal Australian Historical Society 16:120-129.

— 1931, Some Aboriginal animal names. The Australian Zoological Society 6(4):368.

— 1934, Some words from the New England vocabularies. Mankind 1:235-236.

Mathews, R.H., Notebook: 2:35-42.

- Notebook: 4:11-14.

- Notebook: 7:82-88.

- 1903, Languages of the New England Aborigines, NSW. Proceedings of the American Philosophical Society 42:249-263.

Unidentified 1904, Word list headed 'Walcha District' in Science (of Man) 7(4):59-60. 